\title{
Preliminary AIT plan for the FSM segments of GMT
}

Jeong-Yeol Han, Sungho Lee, Sanghyuk Kim, Yunjong Kim, Ueejeong Jeong, et al.

Jeong-Yeol Han, Sungho Lee, Sanghyuk Kim, Yunjong Kim, Ueejeong Jeong, Myung K. Cho, Christoph Dribusch, Bong-Kon Moon, Chang-Hee Kim, Chan Park, Byeong-Gon Park, Youra Jun, Jieun Ryu, Gary Poczulp, Ming Liang, IIKwon Moon, Chanhee Lee, Wongi Lee, Ho-Sang Kim, Paul Gardner, Robert Bernier, Frank Groark, Hugo Chiquito, "Preliminary AIT plan for the FSM segments of GMT," Proc. SPIE 10700, Ground-based and Airborne Telescopes VII, 107002D (6 July 2018); doi: 10.1117/12.2314292

SPIE Event: SPIE Astronomical Telescopes + Instrumentation, 2018, Austin, Texas, United States 


\title{
Preliminary AIT plan for the FSM segments of GMT
}

\author{
Jeong-Yeol Han*a, Sungho Lee ${ }^{\mathrm{a}}$, Sanghyuk Kim ${ }^{\mathrm{a}}$, Yunjong Kim ${ }^{\mathrm{a}}$, Ueejeong Jeong ${ }^{\mathrm{a}}$, Myung K. \\ $\mathrm{Cho}^{\mathrm{b}}$, Christoph Dribusch ${ }^{\mathrm{c}}$, Bong-Kon Moon ${ }^{\mathrm{a}}$, Chang-Hee Kim ${ }^{\mathrm{a}}$, Chan Park ${ }^{\mathrm{a}}$, Byeong-Gon Park ${ }^{\mathrm{a}}$, \\ Youra Jun ${ }^{c}$, Jieun Ryu ${ }^{c}$, Gary Poczulp ${ }^{b}$, Ming Liang ${ }^{b}$, Il-Kwon Moon ${ }^{\mathrm{d}}$, Chanhee Lee ${ }^{\mathrm{e}}$, Wongi \\ Lee $^{\mathrm{e}}$, Ho-Sang Kim ${ }^{\mathrm{e}}$, Paul Gardner ${ }^{\mathrm{f}}$, Robert Bernier ${ }^{\mathrm{f}}$, Frank Groark ${ }^{\mathrm{f}}$, Hugo Chiquito ${ }^{\mathrm{f}}$ \\ ${ }^{a}$ Korea Astronomy and Space Science Institute, Daejeon 34055, Republic of Korea; \\ bational Optical Astronomy Observatory, 950 N. Cherry Ave., Tucson, AZ 85719, USA; \\ ${ }^{c}$ University of Arizona, Tucson, AZ 85721, USA; \\ ${ }^{\mathrm{d}}$ Korea Research Institute of Standards and Science, Daejeon 34113, Republic of Korea; \\ ${ }^{\mathrm{e}}$ Institute for Advanced Engineering, Yongin-si, Gyeonggi-do 17180, Republic of Korea; \\ ${ }^{\mathrm{f}}$ GMTO Corporation, 465 N. Halstead Street, Suite 250, Pasadena, CA 91107, USA
}

\begin{abstract}
The Fast Steering Secondary Mirror (FSM) for the Giant Magellan Telescope (GMT) will have seven $1.05 \mathrm{~m}$ diameter circular segments and rapid tip-tilt capability to stabilize images under wind loading. In this paper, we report on the assembly, integration, and test (AIT) plan for this complex opto-mechanical system. Each fast-steering mirror segment has optical, mechanical, and electrical components that support tip-tilt capability for fine coalignment and fast guiding to attenuate wind shake and jitter. The components include polished and lightweighted mirror, lateral support, axial support assembly, seismic restraints, and mirror cell. All components will be assembled, integrated and tested to the required mechanical and optical tolerances following a concrete plan. Prior to assembly, fiducial references on all components and subassemblies will be located by three-dimensional coordinate measurement machines to assist with assembly and initial alignment. All electronics components are also installed at designed locations. We will integrate subassemblies within the required tolerances using precision tooling and jigs. Performance tests of both static and dynamic properties will be conducted in different orientations, including facing down, horizontal pointing, and intermediate angles using custom tools. In addition, the FSM must be capable of being easily and safely removed from the top-end assemble and recoated during maintenance. In this paper, we describe preliminary AIT plan including our test approach, equipment list, and test configuration for the FSM segments.
\end{abstract}

Keywords: Giant Magellan Telescope, Fast Steering Secondary Mirror, Assembly integration and testing, Plan and procedure, Measurement

\section{INTRODUCTION}

The FSMS assembly of the Giant Magellan Telescope (GMT) consists of seven 1.05-meter segments, six off-axis and one on-axis, each forming an imaging pair with its corresponding primary mirror segment to achieve a common system focus. The FSMS assembly include the FSM segment and the M2 Positioner. The M2 Positioning System provides six-degrees-of-freedom motion for the seven segments relative to the telescope top end and its design concept has been revised since the GMT System Level PDR (SL-PDR) in $2014^{[1]}$. The M2 Positioner is composed of seven short stroke, high precision hexapods called M2 Segment Positioners for segment-to-segment motion and one large stroke, high precision hexapod M2 Global Positioner for positioning the M2 Mirror Cell with all seven segments to compensate for thermal and gravity induced deflections of the Telescope Top End. The FSM segment attach to the M2 Segment Positioners at a kinematic interface allowing the individual FSM segment to be mounted in a repeatable manner.

*jhan@kasi.re.kr; phone: +82 42 865-2147; www.kasi.re.kr

Ground-based and Airborne Telescopes VII, edited by Heather K. Marshall,

Jason Spyromilio, Proc. of SPIE Vol. 10700, 107002D · (C) 2018 SPIE

CCC code: $0277-786 \mathrm{X} / 18 / \$ 18 \cdot$ doi: $10.1117 / 12.2314292$

Proc. of SPIE Vol. 10700 107002D-1 
The FSM development team has been organized to conduct phase 0 study with 3 groups including Design, Mirror Production, and Control System Development ${ }^{[2]}$ based on FSMP development ${ }^{[3]}$. Being based on experiences of FSMP development, KASI leads and manages the FSM project, and has responsibility to assemble and to integrate the components within required tolerances. After finishing of components inspection, FSM components shall be assembled with associated jigs and tools. The assembled components will deliver next steps to make performance test.

FSM system level acceptance test will be done at KASI. Test tower and Testbed frame is to employ for the FSM test at different orientation angles between 0 to 90 degrees. Interferometer, Computer Generated Hologram (CGH), and Laser Tracker will be used to measure Wave Front Error (WFE). Detailed verification plan will be built up during CDR phase. Design work of control system for the test and verification is in progress.

Considering the elevation angle range of the GMT and position angles of the FSM off-axis segments, the off-axis segments should be designed to meet their functional and performance specifications over all orientation angles between 0 to 90 degrees.

\section{PREPARATION FOR ASSEMBLY, INTEGRATION AND TEST}

In order to assemble, integrate, and test, preliminary design of key jigs for the AIT and laboratory environment including clean room, measurement equipment and safety check list are performed and prepared with given requirements as following sub-sections.

\subsection{Preliminary design for assembly and integration jig}

\subsubsection{Mirror holding jig}

Mirror holding jig will be used for both on and off axis mirrors. In this section, preliminary design for the jig was summarized. Conceptual mirror holding jig is depicted in Figure 1. Figure 2 is described assembled mirror and holding jig with different view. In Figure 2, we note that the mirror holding jig is designed to avoid interference with adapter blocks for edge sensors and metrology targets.

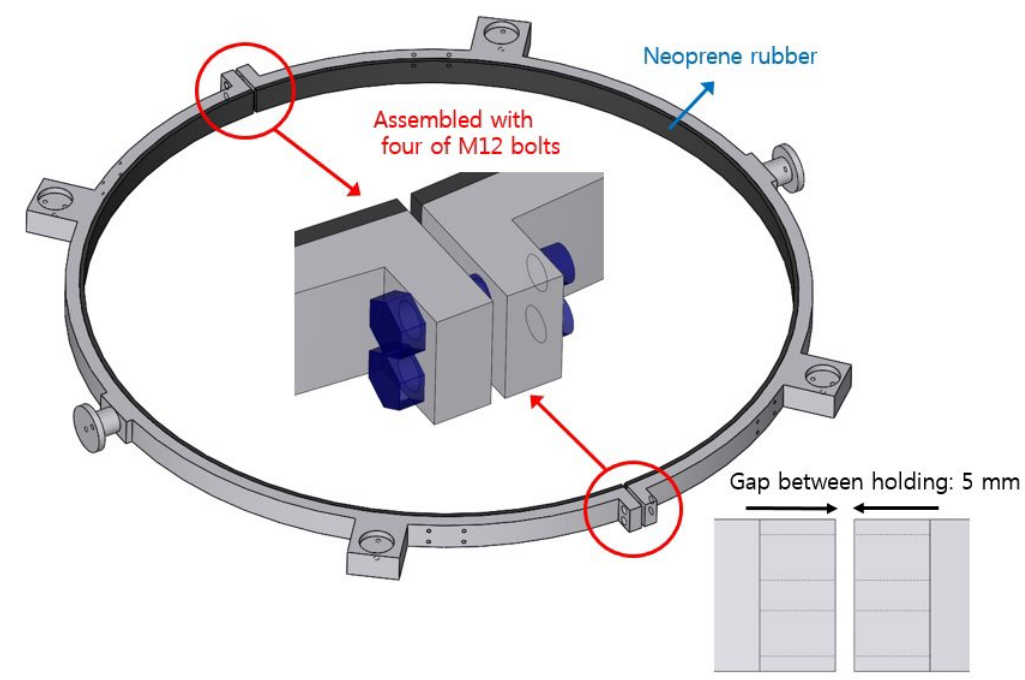

Figure 1. Conceptual mirror holding jig 

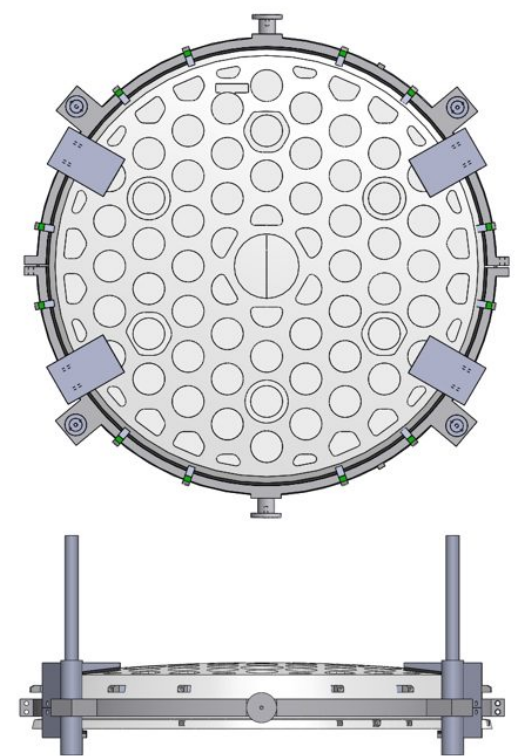

Figure 2. Assembled mirror and holding jig

\subsubsection{Boundary condition and model}

Boundary condition to analyze the jig is summarized as follows:

1. Friction coefficient between mirror and rubber: 0.20 (The coefficient is suggested by a typical minimum static frictional number in between glass and lubricated metal.)

2. Tightening torque for M12 bolts: $20 \mathrm{Nm}$ (friction factor: 0.1 )

3. Load: $5 \mathrm{~g}$ Gravity to Z-axis of the local coordinate of mirror (red arrow in the Figure 3)

4. Fixture: Mounting ears of the jig (green arrows in the Figure 3)

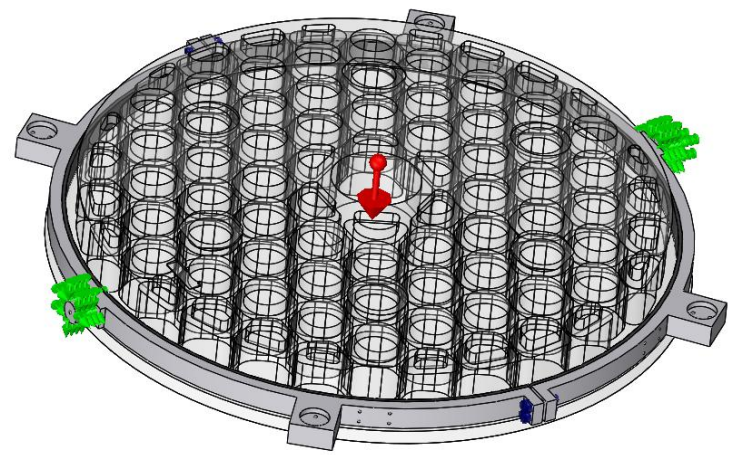

Figure 3. Applied boundary condition onto Mirror Holding Jig

\subsubsection{Result}

We applied 5 g Gravity in Figure 4 (a). The holding jig can hold the mirror under $5 \mathrm{~g}$ Gravity. In addition, estimated maximum stress onto the mirror is $5.202 \mathrm{MPa}$ under the $5 \mathrm{~g}$ Gravity as shown in Figure 4 (b). We try to analyze the displacement under $10 \mathrm{~g}$ Gravity condition as displayed in Figure 4 (c). According to the analysis result, mirror can be detached from the holding jig under $10 \mathrm{~g}$ Gravity condition. Thus, we applied Safety bumper to prevent this safety issue as depicted in Figure 4 (d). 


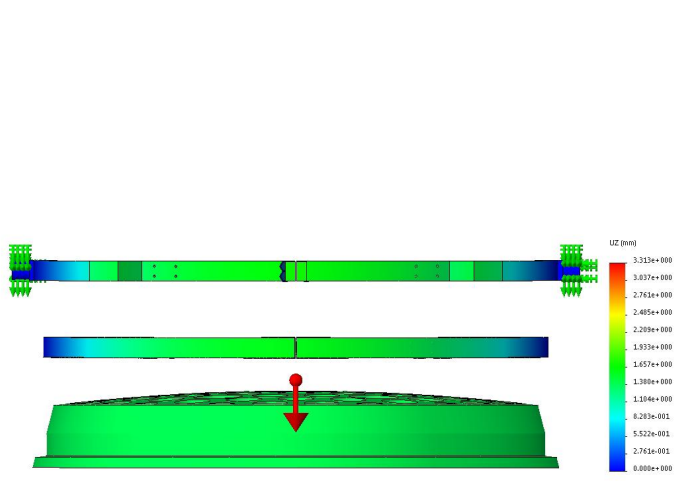

(a)

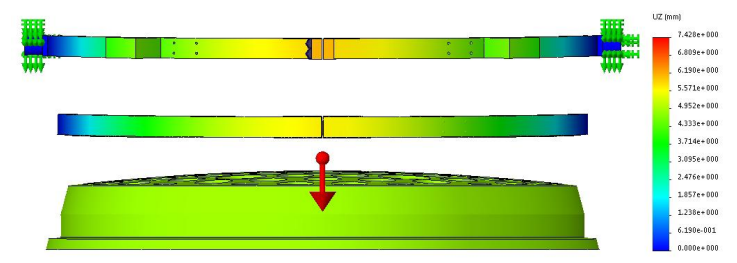

(c)

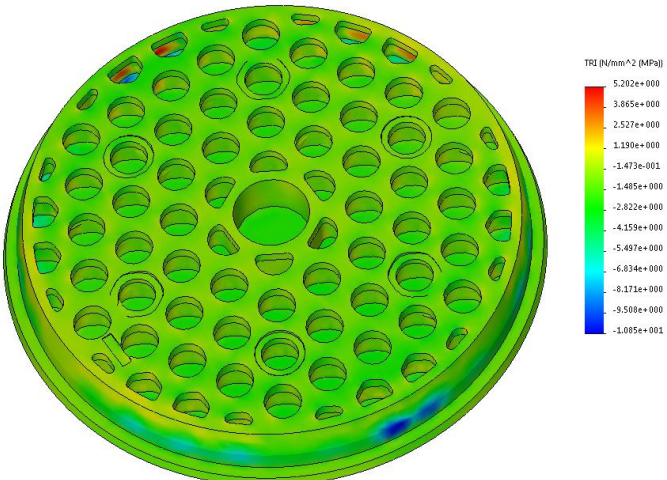

(b)

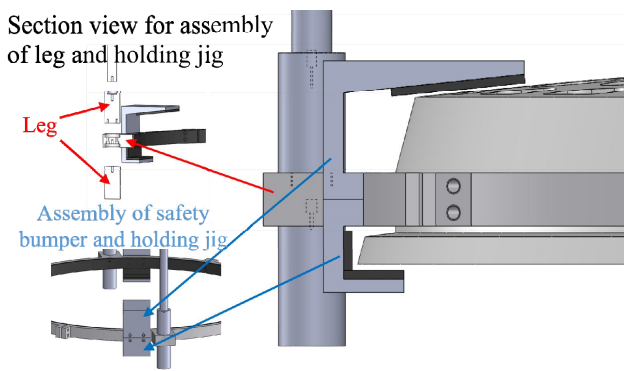

(d)

Figure 4 (a) Analysis result for mirror holding jig with $5 \mathrm{~g}$ gravity condition, (b) Stress analysis for mirror holding jig with $5 \mathrm{~g}$ gravity condition, (c) Analysis result for mirror holding jig with $10 \mathrm{~g}$ gravity condition, and (d) Mirror holding jig with Safety bumper

\subsubsection{Assembly platform}

Assembly platform will be used for assembling of both mirrors and cells. We draw conceptual design for the platform equipped with ten functionality including mirror mount, fine adjustment, and delivery. The adjustment can be achieved by Ball Plungers and Worm Gear, and this hardware can assist to integrate cell and mirror under a hundred-micron level accuracy. Detailed descriptions will be addressed at 3.3.7 section and assembly procedure \#7. In this section, we present the assembly platform design with part labeling as shown in Figure 5. 


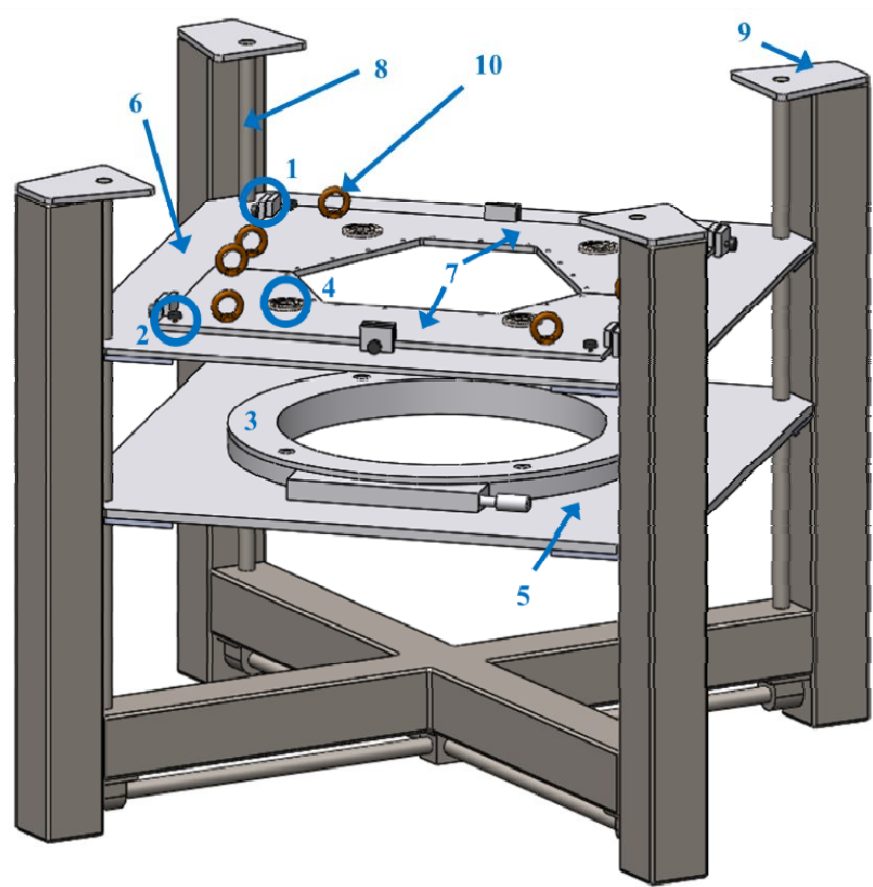

1. Ball plunger for fine adjustment of decenter for Cell

2. Ball plunger for line adjustment ol tip/tilt for Cell

3. Rotation stage for fine adjustment of clocking for Optic

4. Diaphragm for mechanical positioning for mirror and cell

5. Mirror mounting plate

6. Cell mounting plate

7. Cell holding plate

8. LM guide (or TM screw) to move \#5, 6 for up and down

9. Stopper for safety

10. Eye-bolt to handle $\$ 7$

Figure 5 Assembly platform design

\subsection{Laboratory environment for assembly and integration}

\subsubsection{Clean room environment for Assembly and Integration}

The environmental requirements for assembly are constrained by cleanliness level of less than 100,000 class and high temperature limit with less than 50 degrees Celsius. KASI's clean room has been controlled by 10,000 class and 25 degrees Celsius. In addition, the vibration level was examined by 6 different regions (P1 to P6) in the laboratory, and the resulting ISO level was VC-E as shown in Table 2-1. According to the description based on ISO classification, $\mathrm{VC}-\mathrm{E}$ can be assumed to be adequate for the most demanding of sensitive systems including long path, laser-based, small target systems working at nanometer scales, and other systems requiring extraordinary dynamic stability $^{[4]}$. According to the examined data and laboratory specification, KASI's laboratory environment in terms of vibration and cleanliness level is good enough to perform Assembly and Testing.

Table 2-1: Resulting vibration level in the KASI's laboratory

\begin{tabular}{c|c|c|c|c|c}
\hline \multirow{2}{*}{$\mathrm{P} 1$} & $\mathrm{P} 2$ & $\mathrm{P} 3$ & $\mathrm{P} 4$ & $\mathrm{P} 5$ & $\mathrm{P} 6$ \\
\hline $\mathrm{VC}-\mathrm{F}$ & $\mathrm{VC}-\mathrm{G}$ & $\mathrm{VC}-\mathrm{G}$ & $\mathrm{VC}-\mathrm{G}$ & $\mathrm{VC}-\mathrm{E}$ & $\mathrm{VC}-\mathrm{G}$ \\
1.02 & 0.41 & 0.53 & 0.42 & 2.12 & 0.43 \\
$\mu \mathrm{m} / \mathrm{s} @ 63 \mathrm{~Hz}$ & $\mu \mathrm{m} / \mathrm{s} @ 63 \mathrm{~Hz}$ & $\mu \mathrm{m} / \mathrm{s} @ 10 \mathrm{~Hz}$ & $\mu \mathrm{m} / \mathrm{s} @ 10 \mathrm{~Hz}$ & $\mu \mathrm{m} / \mathrm{s} @ 8 \mathrm{~Hz}$ & $\mu \mathrm{m} / \mathrm{s} @ 10 \mathrm{~Hz}$ \\
\hline $\mathrm{VC}-\mathrm{G}$ & $\mathrm{VC}-\mathrm{G}$ & $\mathrm{VC}-\mathrm{G}$ & $\mathrm{VC}-\mathrm{G}$ & $\mathrm{VC}-\mathrm{E}$ & $\mathrm{VC}-\mathrm{G}$ \\
0.73 & 0.46 & 0.38 & 0.45 & 2.27 & 0.65 \\
$\mu \mathrm{m} / \mathrm{s} @ 63 \mathrm{~Hz}$ & $\mu \mathrm{m} / \mathrm{s} @ 63 \mathrm{~Hz}$ & $\mu \mathrm{m} / \mathrm{s} @ 10 \mathrm{~Hz}$ & $\mu \mathrm{m} / \mathrm{s} @ 50 \mathrm{~Hz}$ & $\mu \mathrm{m} / \mathrm{s} @ 10 \mathrm{~Hz}$ & $\mu \mathrm{m} / \mathrm{s} @ 10 \mathrm{~Hz}$ \\
\hline $\mathrm{VC}-\mathrm{E}$ & $\mathrm{VC}-\mathrm{F}$ & $\mathrm{VC}-\mathrm{E}$ & $\mathrm{VC}-\mathrm{F}$ & $\mathrm{VC}-\mathrm{E}$ & $\mathrm{VC}-\mathrm{E}$ \\
2.45 & 0.94 & 1.72 & 1.24 & 2.22 & 1.85 \\
$\mu \mathrm{m} / \mathrm{s} @ 63 \mathrm{~Hz}$ & $\mu \mathrm{m} / \mathrm{s} @ 63 \mathrm{~Hz}$ & $\mu \mathrm{m} / \mathrm{s} @ 25 \mathrm{~Hz}$ & $\mu \mathrm{m} / \mathrm{s} @ 20 \mathrm{~Hz}$ & $\mu \mathrm{m} / \mathrm{s} @ 80 \mathrm{~Hz}$ & $\mu \mathrm{m} / \mathrm{s} @ 20 \mathrm{~Hz}$ \\
\hline
\end{tabular}




\subsubsection{Key equipment for AIT}

Key equipment for AIT is summarized in Table 2-2.

Table 2-2: Key equipment for AIT

\begin{tabular}{|c|c|c|c|c|}
\hline $\begin{array}{c}\text { Equipment/co } \\
\text { mponent }\end{array}$ & Model \# & Performance & Photo/Drawing & Note/Application \\
\hline Interferometer & PhaseCam 5030 & Accuracy: $<0.002$ wave & & $\begin{array}{c}\text { Measurement for figure } \\
\text { error }\end{array}$ \\
\hline Laser Tracker & $\begin{array}{c}\text { FARO vantage tracker } \\
\text { system }\end{array}$ & $\begin{array}{l}\text { Accuracy: } 15 \mathrm{um} \\
\text { Range: } 80 \mathrm{~m}\end{array}$ & & $\begin{array}{c}\text { Measurement for mirror cell } \\
\text { displacement }\end{array}$ \\
\hline CMM & $\begin{array}{l}\text { FARO Edge and } \\
\text { ScanArm ES }\end{array}$ & $\begin{array}{l}\text { Measuring range: } 2.7 \mathrm{~m} \\
\text { Point repeatability: } 29 \mathrm{um}\end{array}$ & & $\begin{array}{c}\text { Measurement for } \\
\text { mechanical dimension }\end{array}$ \\
\hline Hexapod & H-950.H12 & $\begin{array}{l}\text { Loading capacity: } 250 \mathrm{~kg} \\
\text { Speed: } 0.5 \mathrm{~mm} / \mathrm{s}\end{array}$ & & High precision mount \\
\hline $\begin{array}{l}\text { Eddy Current } \\
\text { Sensor }\end{array}$ & KAMAN KD-5100 & $\begin{array}{l}\text { Nonlinearity: up to } \pm 0.5 \% \\
\text { FSO } \\
\text { RMS input displacement } \\
\text { resolution: } \\
\sqrt{10^{-7} \sqrt{B W(\mathrm{~Hz})} m m}\end{array}$ & & Measurement for Tilt angle \\
\hline
\end{tabular}

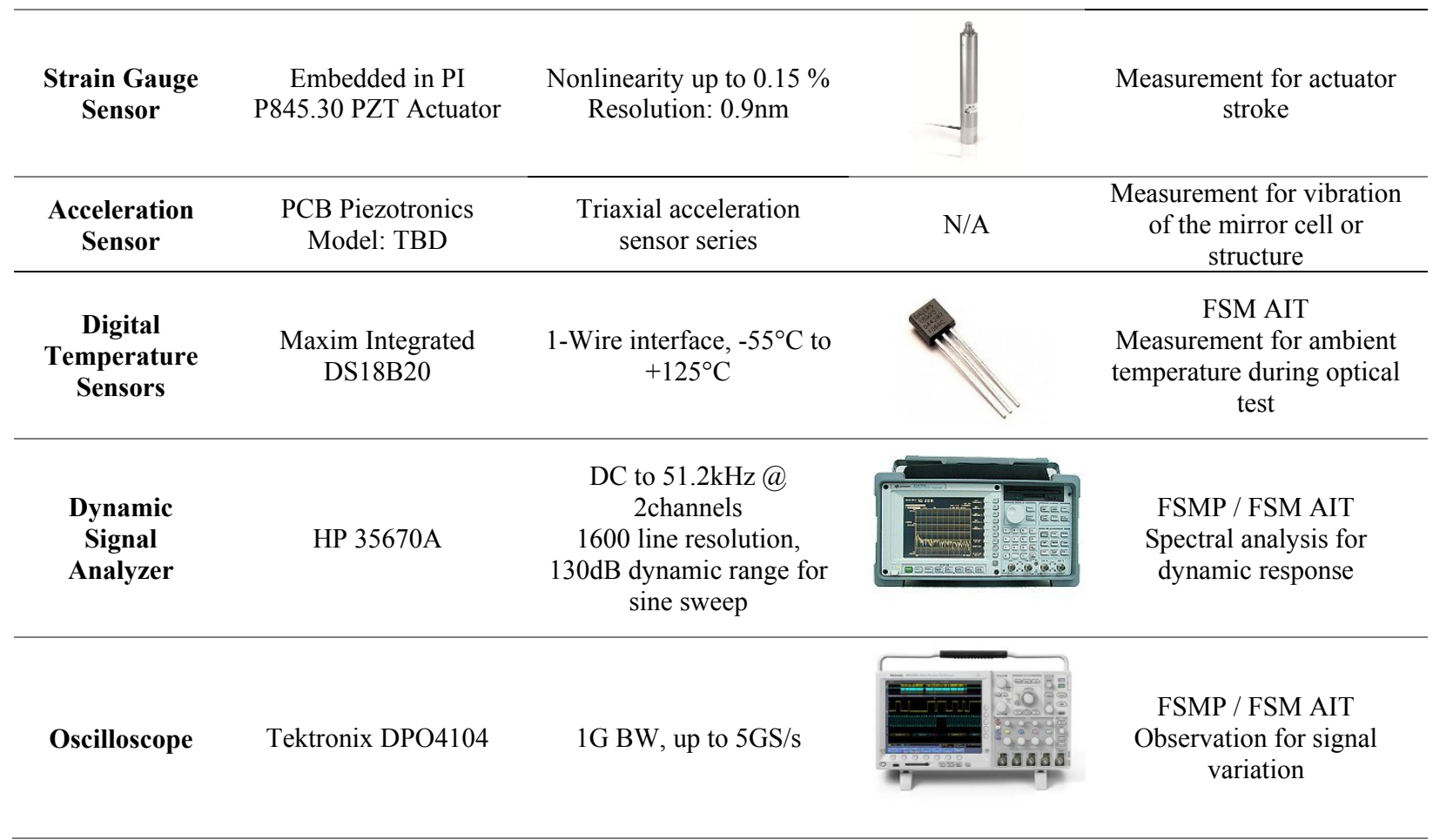




\subsection{Safety}

Safety check list is collected by 4 categories.

2.3.1 FSM optic safety: FSM optic protective cover provided by Mirror Vendor for each segment is to protect the optical surface during maintenance and transportation.

2.3.2 FSM safety integrity compliance: The FSM local safety system shall meet the requirements of Safety Integrity Level 3 according to the IEC 51508.

2.3.3 FSM local safety module: The safety module is for equipment or personnel. The safety module works even when the FSM device control is abnormal or stopped.

2.3.4 FSM handling safety: FSM will secure safety for handling jig design. An education and training will be applied to participants involved in the assembly steps.

\section{ASSEMBLY, INTEGRATION AND TEST PLAN}

\subsection{Overall AIT flow}

Overall AIT flow including component acceptance test is shown in Figure 6. Components including mirror, mechanical parts and control parts will be made component acceptance test as a first step. Mirror, holding jigs, BAS, Lateral and Axial support, Seismic restraint, Vacuum seal, Wind cover, Aperture mask, and Metrology target is assembled and integrated using assembly platform, holding jig and adaptable tools at the second steps. In the third step, integrated FSM is tested by three functions such as vacuum control, optical performance, and tip-tilt performances. After finished performance test, mirror and cell will be packed and shipped to the collimation test site.

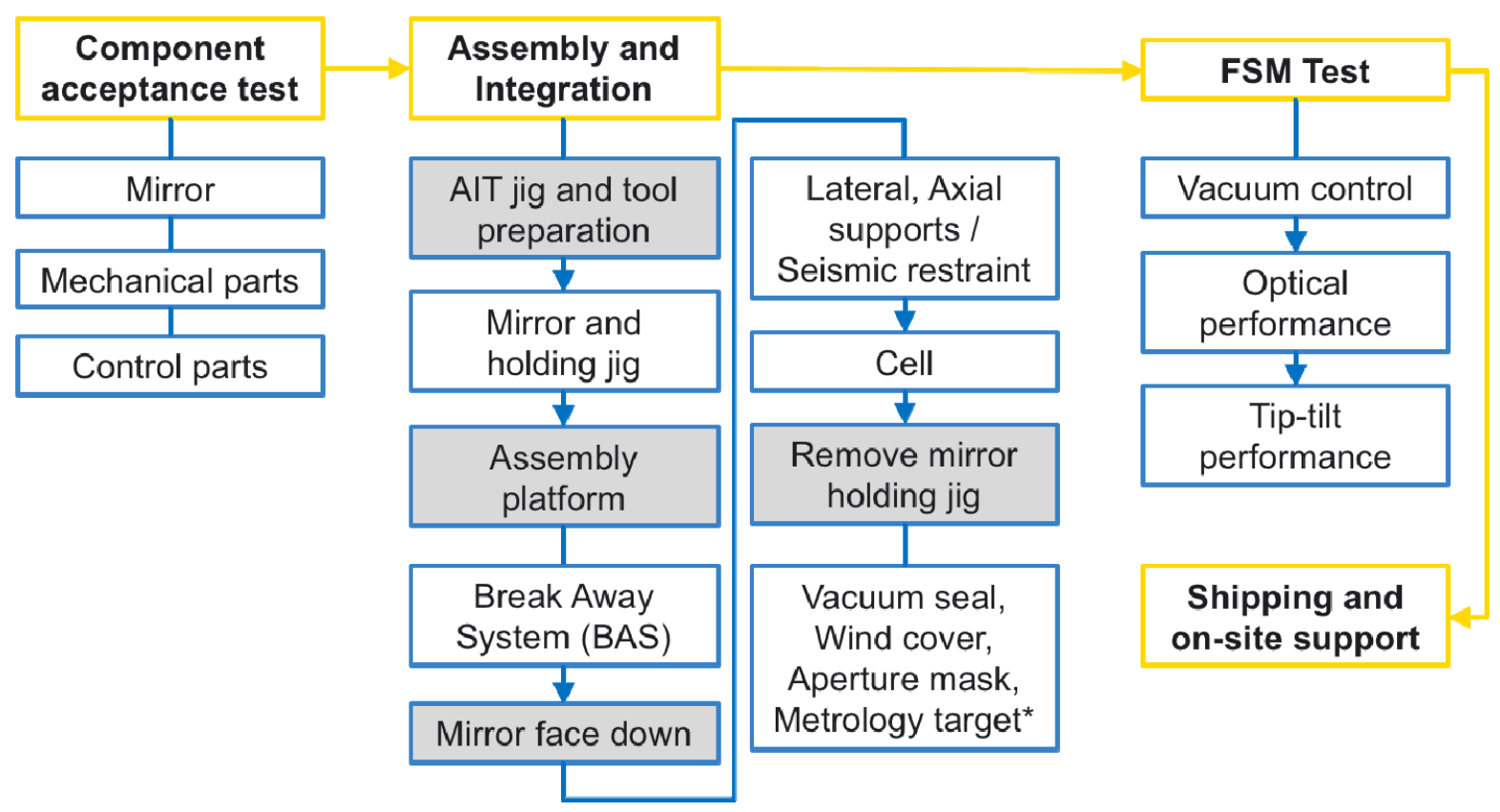

Figure 6 Overall AIT flow 


\subsection{Assemble the Sub-Assembly parts}

\subsubsection{Axial support sub-assembly including BAS}

Axial support sub-assembly will be assembled prior to system assembly which is described by following subsections. The sub-assembly is included in Piezo actuator, spring, Flexures, and BAS. The BAS can be separated by spring and adapter parts as shown in Figure 7. We will check mechanical size of the sub-assembly parts within tolerances using CMM and assemble the parts carefully with assembly locations.

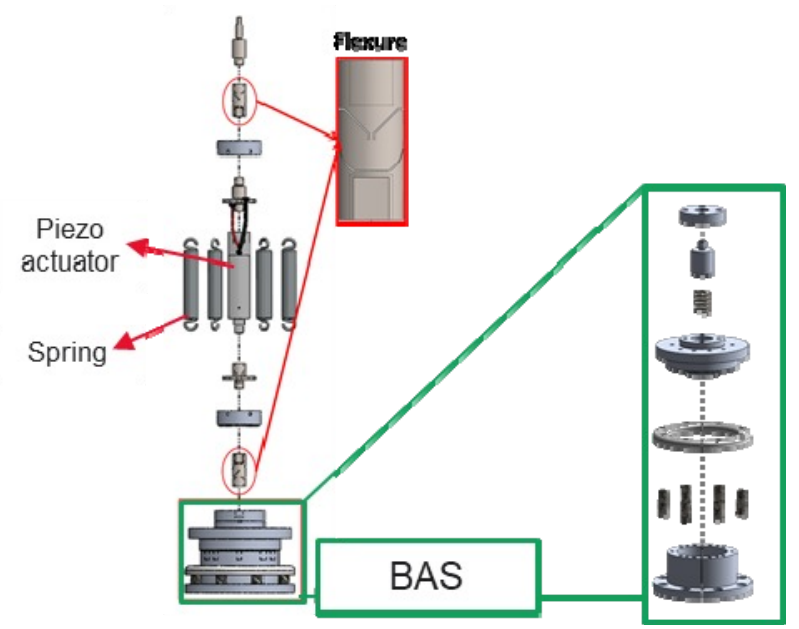

Figure 7 Axial support sub-assembly parts

\subsubsection{Seismic restraint}

Seismic restraints are composed of five parts as shown in the exploded view of Figure 8 (a). All 5 parts will be fixed with concentric location after mechanical tolerance checking. Figure 8 (b) represents a bend to shrink the leg of Seismic bumper when the bumper is installed on the back side of the mirror.

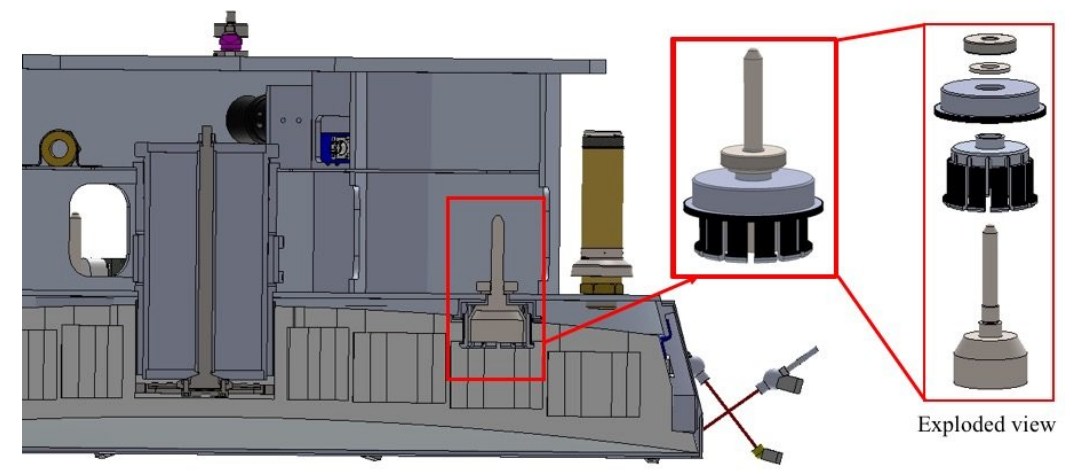

(a)

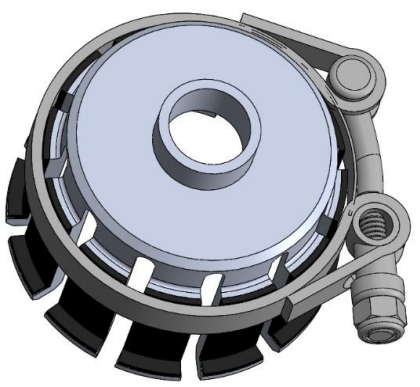

(b)

Figure 8 (a) Seismic restraint parts and (b) Seismic bumper leg and bend wrap to shrink the leg

\subsubsection{Vacuum seal, Wind cover, and Aperture mask}

Vacuum seal, Wind cover, and Aperture mask will be assembled during FSM AIT procedure \#8 as introduced in following section. 


\subsection{Assembly and Integration procedure}

3.3.1 Take mirror out of box: Take mirror our of box using mirror handling fixture and holding jig assembly as shown in Figure 9.

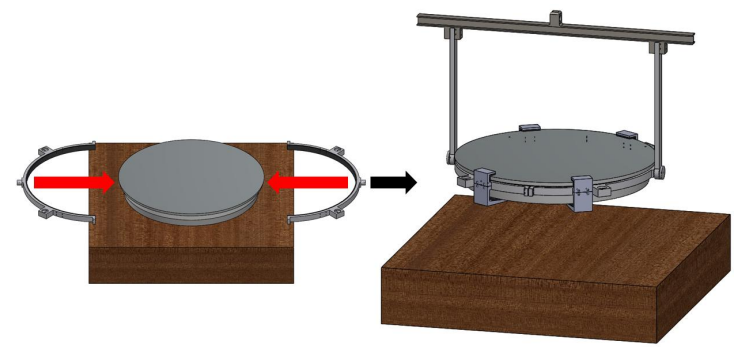

Figure 9 Assembly procedure \#1: Take mirror out of mirror shipping box

From Install the mirror onto the assembly platform to assemble the sub-assembly parts: Assembly procedure \#2 to \#5 are explained by following sections and described on Figure 10 (a) to (d).

3.3.2 Install the mirror onto the assembly platform: Install the mirror onto the Assembly Platform.

3.3.3 Assemble Break Away System (BAS): Assemble the BAS under the mirror.

3.3.4 Flip Mirror to face down: Flip the mirror to face down orientation.

3.3.5 Assemble the sub-assembly parts: Assemble the Lateral support sub-assembly, Seismic restraints and Axial supports sub-assembly, and Tangential support.

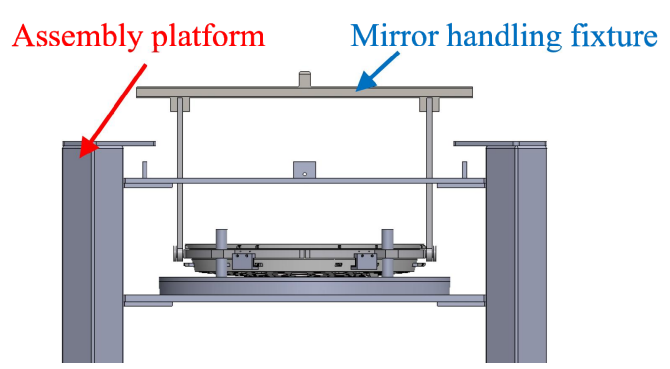

(a)

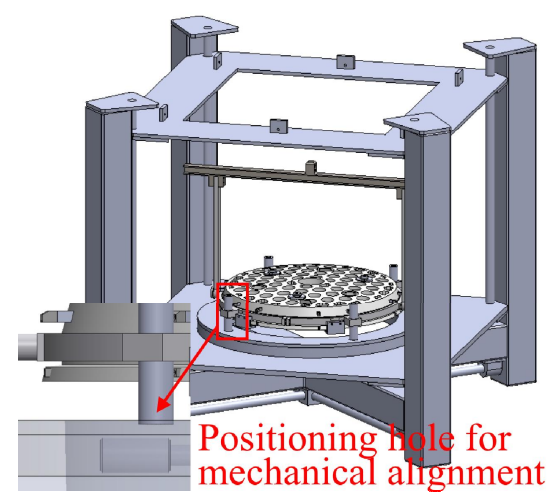

(c)

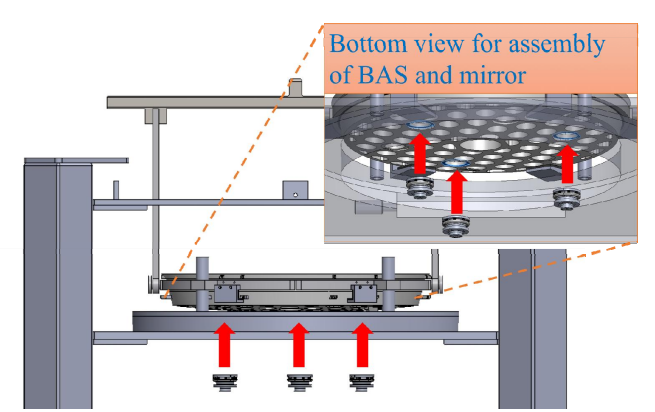

(b)

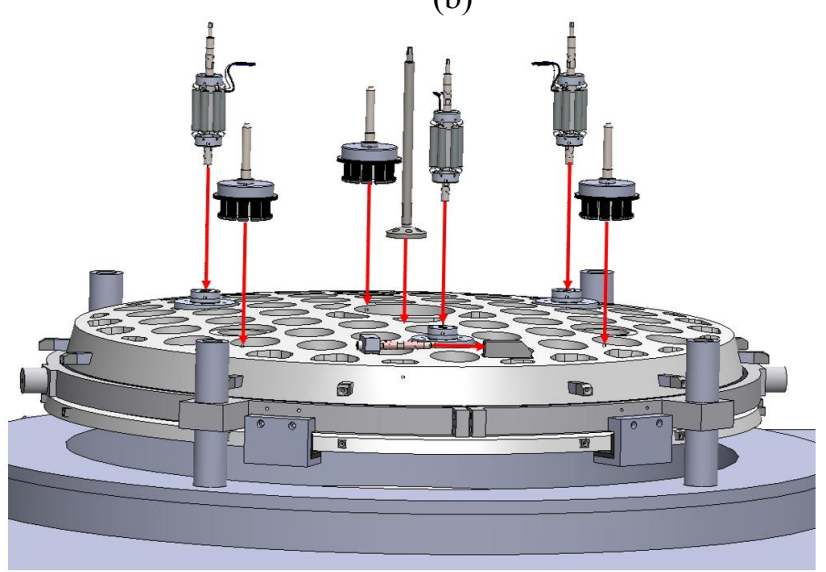

(d)

Figure 10 (a) Assembly procedure \#2: Install the mirror onto the Assembly platform, (b) Assembly procedure \#3: Assemble the BAS to mirror, (c) Assembly procedure \#4: Flip mirror to face down, and (d) Assembly procedure \#5:

Assemble sub-assembly parts 


\subsubsection{Install the cell onto the Cell Plate}

Install the cell onto the Cell Plate of Assembly Platform as shown in Figure 11.

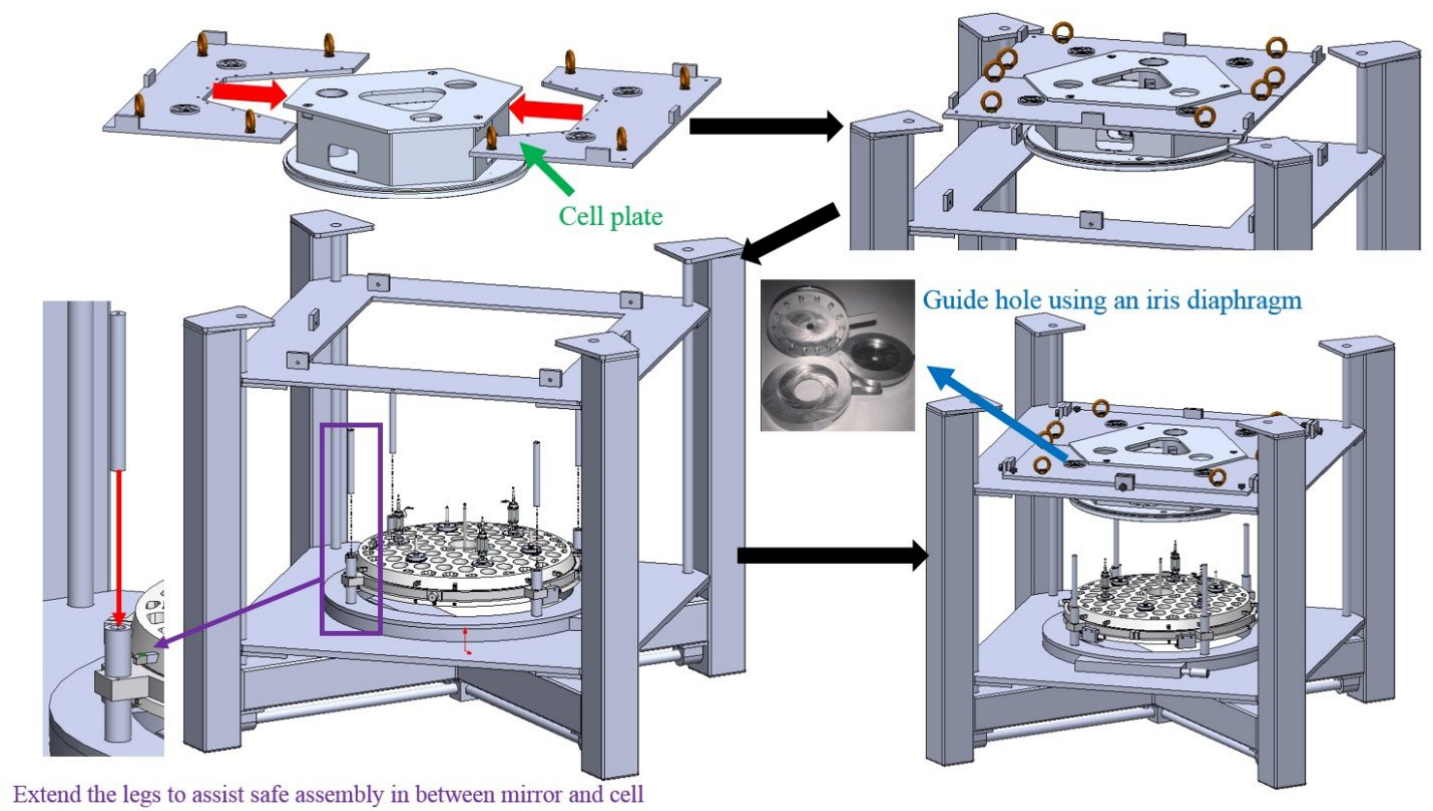

Figure 11 Assembly procedure \#6: Install the cell onto the Cell Plate of Assembly Platform

\subsubsection{Assemble the Mirror and Cell}

Assemble the Mirror and Cell with adjustment mechanism as depicted in Figure 12. In this procedure, we try to adjust within $3 \mathrm{~mm}$ in position accuracy using Guide Pin and Iris Diaphragms. For more accurate adjustment, we will use Ball Plungers and Worm Gear. CMM and Laser Tracker will be used to check positions of Mirror and Cell. The Spherolinder Mounting Adapter in Cell will be installed in Assembly and Integration procedure. The Spherolinder adapter would be an interface part in between Cell in FSM segment and hexapod in M2 Positioner.

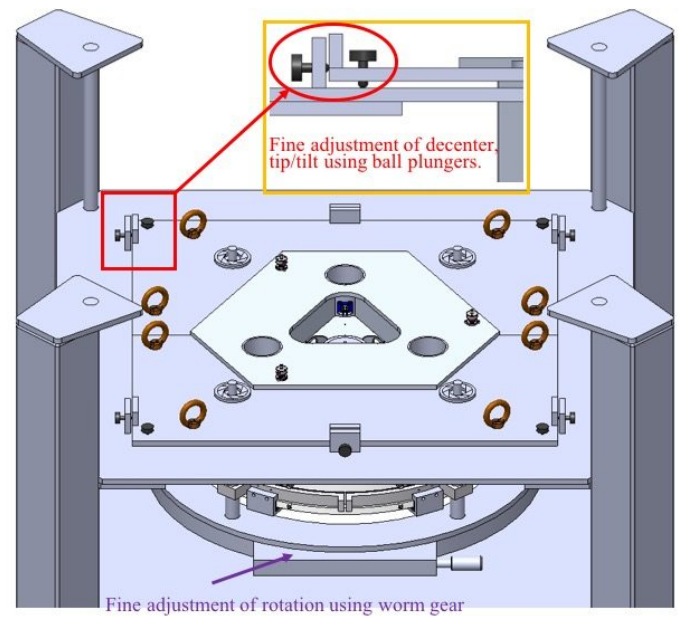

Figure 12 Assembly procedure \#7: Asssemble the Mirror and Cell 


\subsubsection{Remove the Mirror Holding Jig Assembly and install Vacuum parts, Wind shield, and Aperture mask}

To eliminate the mirror holding jig assembly and to install the Vacuum Seal, Wind shield, and Aperture Mask are as shown in Figure 13. Vacuum parts are included in Proportional valve, Pressure relief, Vacuum relief, Pressure sensor, 3-way hose connector, Pressure regulator, and check valve as described in Figure 13 (a). Commercial PVC or 3M Tape can be applied to seal mirror and mirror cell as depicted in Figure 13 (b). In Figure 13 (c), Wind shield is attached with eighteen M4 bolts at the middle of mirror cell. One-piece Aperture mask is assembled by twenty-five M4 bolts with Wind shield as shown in Figure 13 (d).

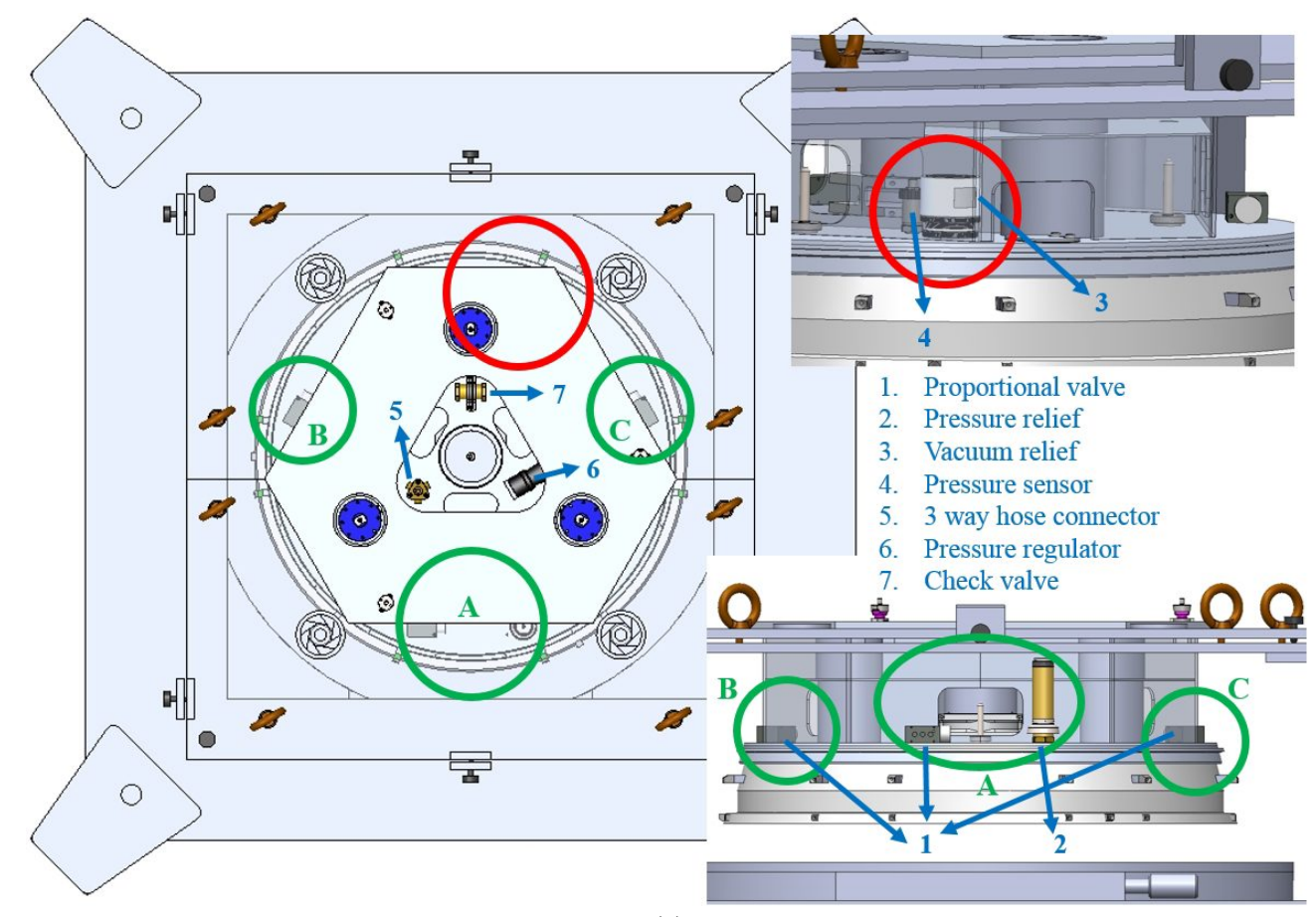

(a)

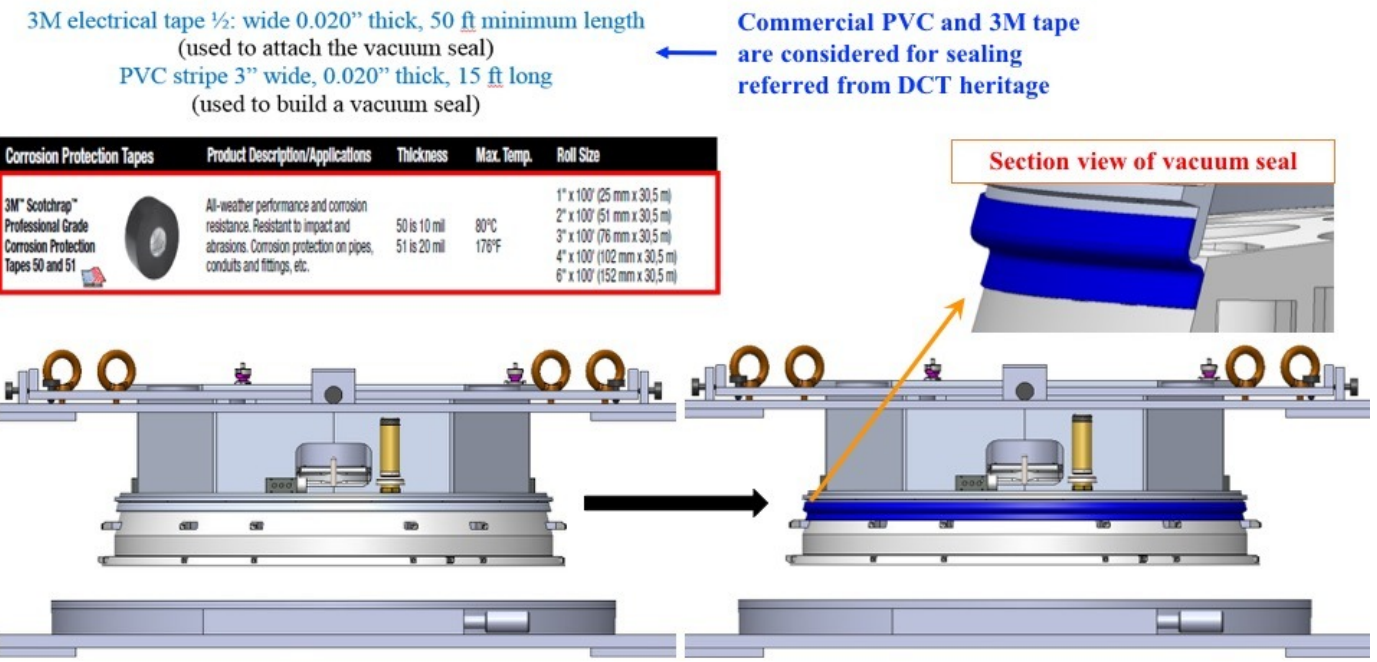

(b) 

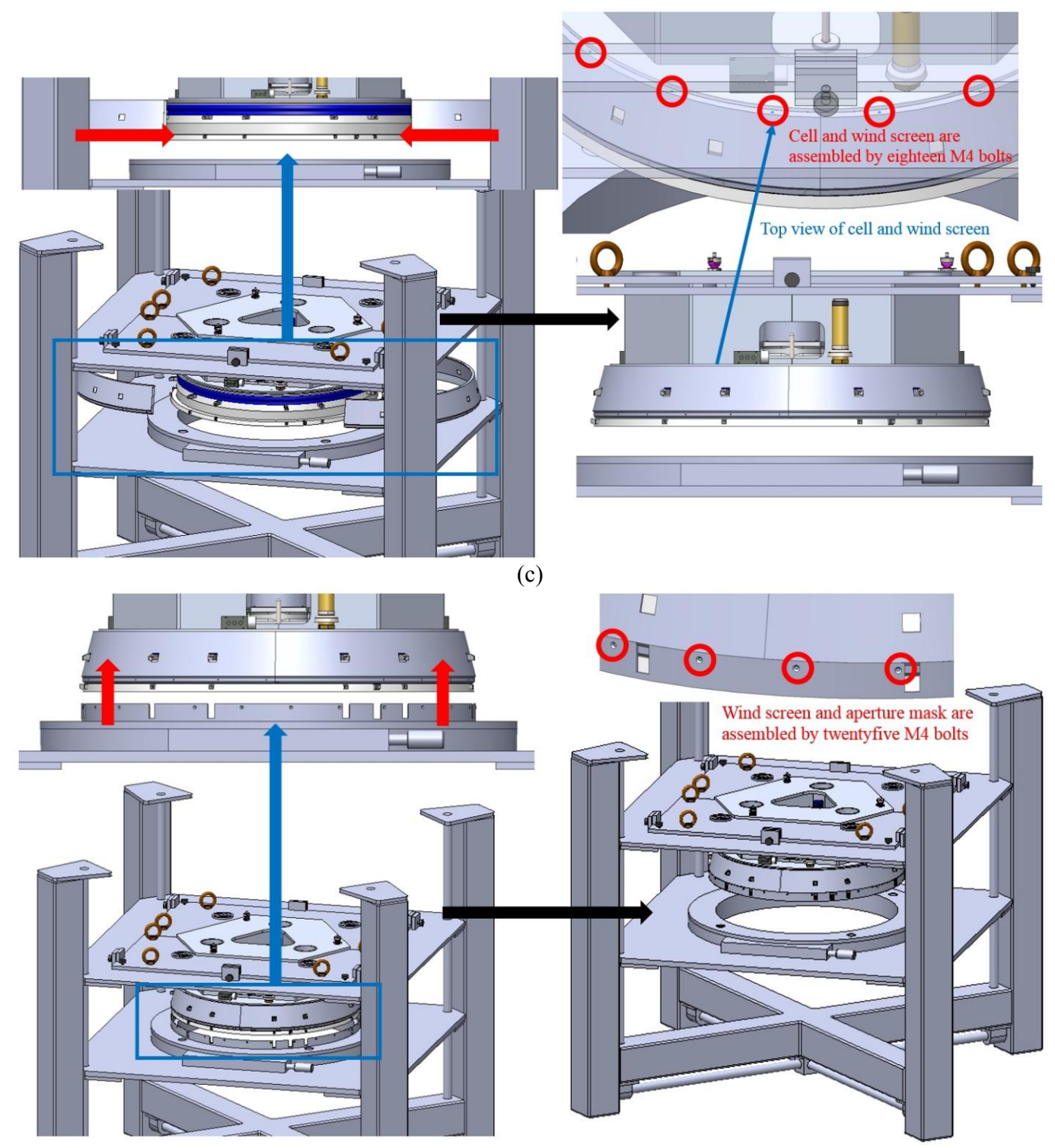

(c)

\section{(d)}

Figure 13 Assembly procedure \#8: (a) Remove the Mirror Holding Jig Assembly and install vacuum parts, (b) Attach vacuum seal, (c) Install Wind shield, and (d) Install aperture mask

\subsubsection{Install the FSM to the Testbed Frame}

Installation of the FSM to the Testbed Frame or M2 Positioner is shown in Figure 14. Positional tolerance relative to the M2 positioner interface will be less than manufacturing margin within $0.1 \mathrm{~mm}$ in length. 


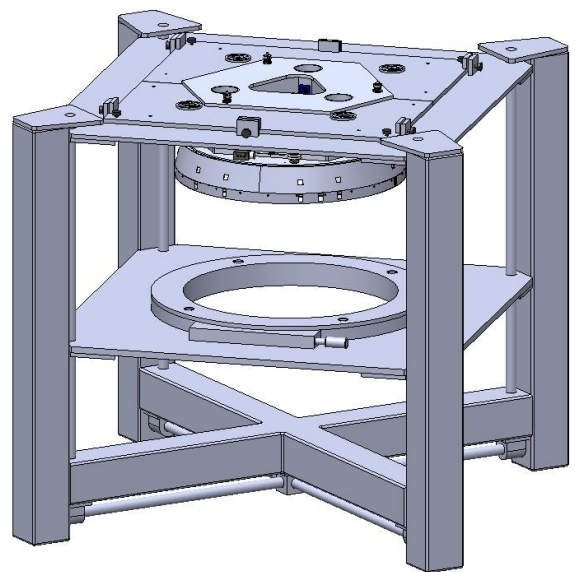

Figure 14 Assembly procedure \#9: Install the FSM to the Testbed Frame or M2 Positioner

\subsection{Test plan}

\subsubsection{Optical test}

According to a draft verification matrix, test item allocated by KASI is identified by zenith angle range, total surface error, and FSM acceptance and testing functionality. In order to provide functional and performance specifications to meet those requirements between Zenith angle 0, 45 (TBD), and 90 in degrees, KASI plans to equip testing tower with moving capability and interferometer with precise adjustable jigs.

Principal optical test will be made WFE from interferogram using CGH and interferometer. Each FSM segment is composed of mirror, mirror cell and control equipment. To obtain interferogram, CGH and interferometer shall be mounted with at least 6-axis stages including 3 linear translations, tip-tilt and clocking. Figure 15 shows a schematic configuration without mounting jigs on test tower to acquire optical performances such as WFE and relevant interferograms.

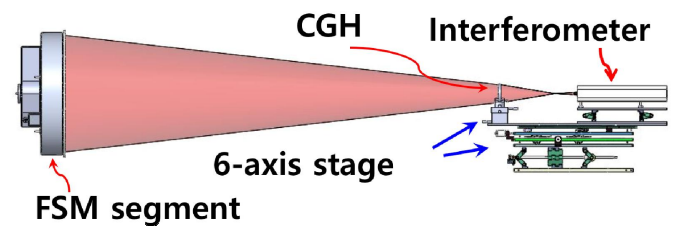

(a)

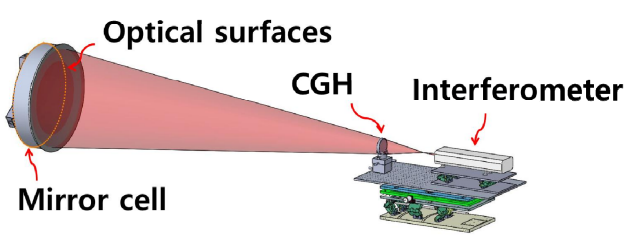

(b)

Figure 15 Schematic configurations without mounting jigs to test optical performances for FSM segment in both (a) side and (b) isometric view

In order to test optical, mechanical, and dynamic performance for integrated FSM segment at different orientations of 0, 45 (TBD), and 90 degrees, KASI shall equip test tower and mechanical mounting jigs to adjust angles for FSM optic and interferometer including CGH and 6-axis degrees of freedom (DOF) stages. Figure 16 describes schematic test configuration to measure optical performances including total surface error on three different angles. Mirror cell is fixed at Testbed in the mounting plate. 


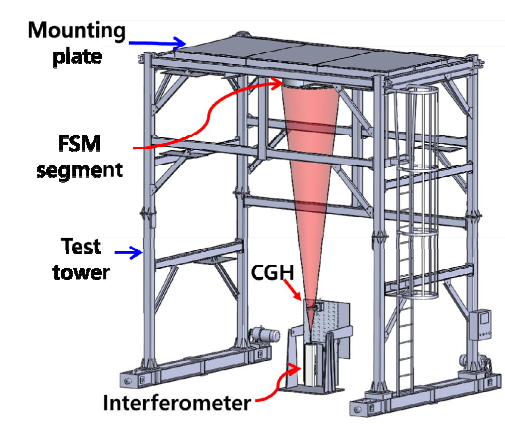

(a) Test configuration at Zenith angle $0^{\circ}$

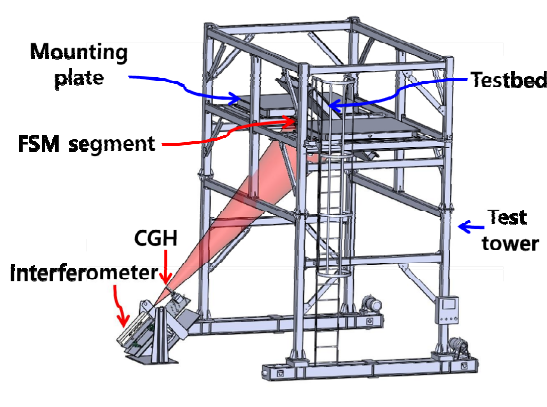

(b) Test configuration at angle $45^{\circ}$

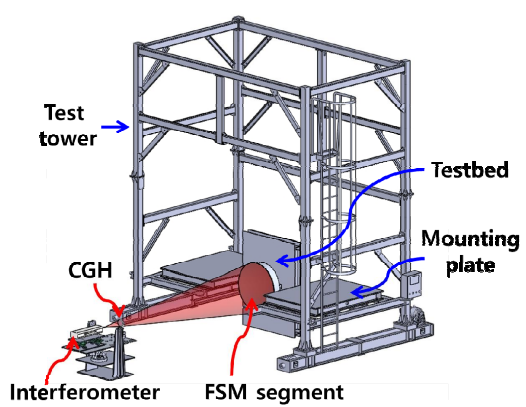

(c) Test configuration at angle $90^{\circ}$

Figure 16 Schematic test configurations at 3 different angles of (a) Zenith angle $0^{\circ}$, (b) angle $45^{\circ}$, and (c) angle $90^{\circ}$

\subsubsection{Mechanical and Control test}

Fast-steering performance of the FSM will be tested using an eddy current sensor that can measure tip/tilt motion with accuracy of $0.9 \mathrm{~nm}$ which should be sufficient since resolution of the actuator is approximately $60 \mathrm{~nm}$. A SMR and an accelerometer (TBD) will be installed at the cell or the testing tower to verify the dynamic coupling of mirror and structure due to the tip/tilt.

Time series monitoring, and analysis of a differential pressure gauge and load cells will be performed to confirm stability of the vacuum control system.

Figure 17 describes the system architecture to measure dynamic performance of the FSM. A piezoelectric actuator is controlled by E-727.3SDAF and tip/tilt mechanics code on the Linux-based EtherCAT master computer. Two axes of eddy current sensors (proximity sensor) will be installed at the cell edge to measure the tip/tilt angle of the mirror. In addition, we have a plan to use the LVDT probes they will be attached on backside of the mirror. However, the installation position and attachment method need to be determined. We will clearly define the plan for the LVDT at the start of the next phase. The command signal output for the piezoelectric actuators, measured value by the eddy current sensor and actuator-embedded strain gauge sensor will be acquired through the NI analog input modules to analyze the result of the test. The FSM employs a vacuum support system to assist fast tip/tilt motion and to compensate the mirror gravity. The balancing between gravity and pressure is achieved by vacuum control system that consists of load cells, a buffer tank, a vacuum pump, and proportional valves. Two or more triaxial acceleration sensors and SMRs will be placed on the mirror cell to measure possible vibrations induced by mirror/cell interaction during the tip/tilt motion. An acquisition module for the acceleration sensors and a laser tracker for the SMRs will be used to acquire the vibration data. The laser tracker can detect micrometer-level vibration and the accelerometer might measure sub micrometer-level vibration. KASI plans to use eight PT100 temperature sensors to monitor temperatures of the mirror cell and electronics cabinet. The ambient temperature of the test tower will be obtained by using twenty or more DS18B20 digital temperature sensors to monitor aerodynamic stability. Detailed procedures are explained by FSM control system description ${ }^{[5]}$. 


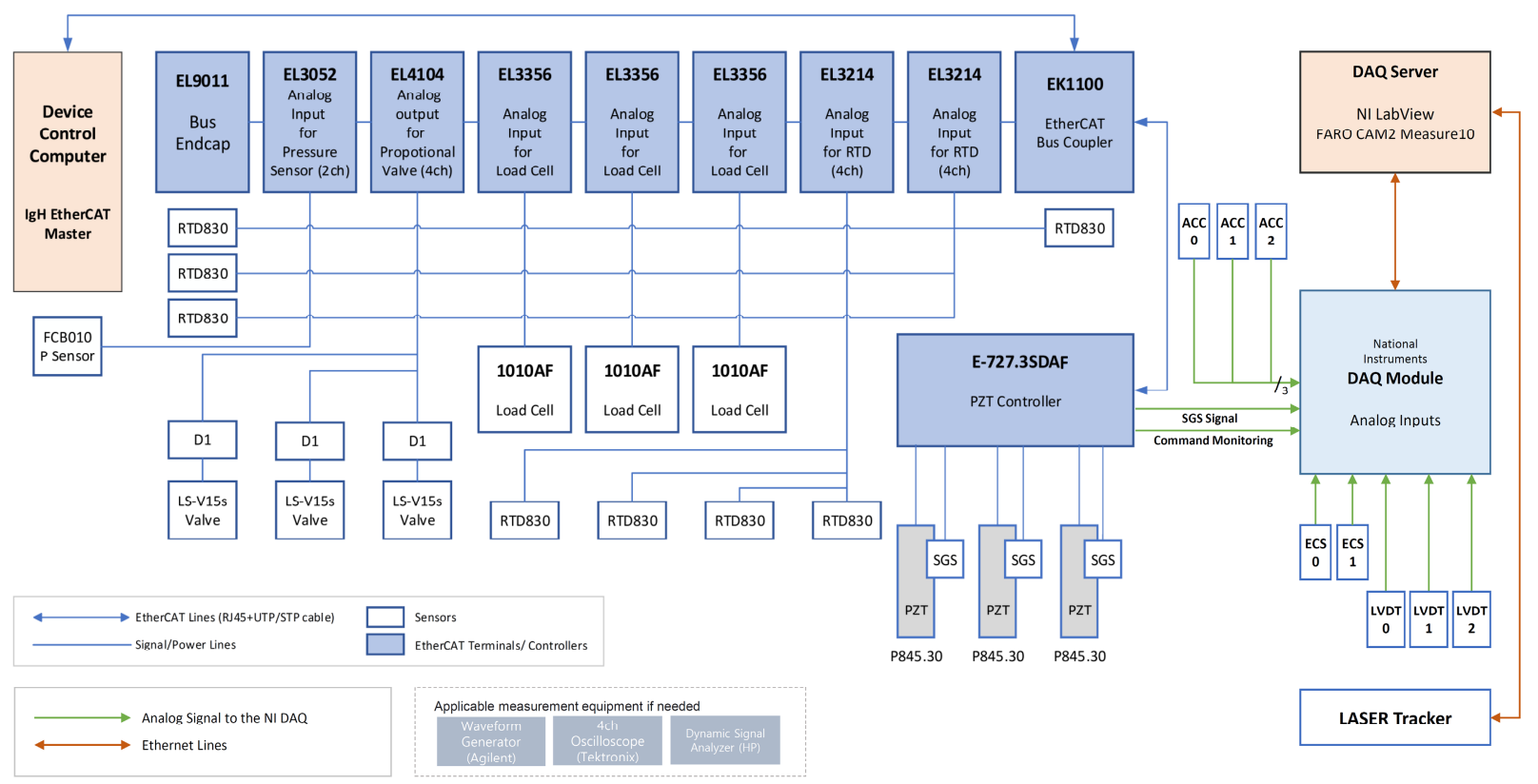

Figure 17 System architecture to measure the mechanical performance of the FSM

\section{CONCLUSION}

As the preliminary design stage of the FSM development project, preliminary AIT plan is summarized for this complex opto-mechanical system. All components including polished and lightweighted mirror, lateral and axial support assemblies, seismic restraints, and mirror cell was connected logically to meet given required mechanical and optical tolerances for appropriate assembly, integration and test. We plan to assemble components and subassemblies and then test optically and dynamically in different orientations using precision tooling, jigs, and measurement equipment.

\section{REFERENCES}

[1] GMTO Corp, “GMT System Level Preliminary Design Review,” (2014) http://www.gmto.org/resources/slpdr/

[2] Lee, S. et al., "Development of the fast steering secondary mirror assembly of GMT," Proc. SPIE 9912, 991241 (2016)

[3] Kim, Y. -S. et al., "Development status of the prototype of the GMT fast steering mirror," Proc. SPIE 8415, 84150B (2012)

[4] Vibration Criteria of ISO is presented in homepage of 'minus k Technology' (www.minusk.com).

[5] Jeong, U. et al., "Design and prototype test of control systems for the fast-steering secondary mirror of GMT,” Proc. SPIE, 10700-146 (2018) 